\title{
Electron Energy Loss Near-Edge Structures in Complex Perovskites
}

\author{
G.A. Botton ${ }^{1,2}$, C. Maunders ${ }^{1}$, Y. Shao ${ }^{1}$, M.-Y. Wu ${ }^{2}$, S. Lazar ${ }^{2}$, J. Etheridge ${ }^{3}$, H. J. Whitfield ${ }^{3}$ \\ ${ }^{1}$ Department of Materials Science and Eng., BIMR, McMaster University, Hamilton, Ont., Canada \\ ${ }^{2}$ National Centre for HREM, Delft University of Technology, Delft, The Netherlands \\ ${ }^{3}$ Department of Materials Engineering, Monash University, Victoria, 3800, Australia
}

High-resolution electron energy loss spectroscopy (EELS) provides better sensitivity to fine structures related to bonding in complex materials [1,2]. Using monochromators and improved spectrometers it is possible to achieve $0.1 \mathrm{eV}$ resolution with symmetric zero-loss peak profiles leading to improved detection of both core-loss and low-loss features [3] in EELS spectra. This capability makes it possible to study systematically changes in bonding in materials that present interesting physical properties. Oxides with the perovskite structure provide an interesting playing field to study many fundamental changes in structure and physical properties when systematic substitutions of atoms in the crystals are made in a controlled fashion. Substitutions of Ti atoms in $\mathrm{BaTiO}_{3}$ with other transition metals provide ingenious ways to change the stability of the basic structure and induce phase transformations. For example, Mn substitutions for $\mathrm{Ti}$ in $\mathrm{BaTiO}_{3}$ stabilize the hexagonal phase at room temperature and it has been proposed that this is due to increased metal-metal bonding between adjacent face-sharing octahedra [4]. EELS measurements in $\mathrm{Ba}(\mathrm{Ti}, \mathrm{Mn}) \mathrm{O}_{3}$, however, have shown that, with respect to the tetragonal structure, there are only subtle changes in the oxygen $\mathrm{K}$ edge fine structures of the hexagonal compound due to overlaps of the Mn $3 d$ electrons and $\mathrm{O} 2 p$ electrons while the Ti environment is not altered significantly [5]. Ru substitutions for Ti also lead to the stabilization of the hexagonal phase but there are no reports on the effect of the changes in the near-edge structures related to the structural changes. For this particular case, it is of great interest, to study the closely related hexagonal perovskite $\mathrm{BaRuO}_{3}$. Probing electronic structure changes in these two materials with respect to $\mathrm{BaTiO}_{3}$ makes it possible to gain insight on both the electronic structure of these closely related compounds and the origin of the structural changes. We have therefore used EELS with high energy resolution to probe the near edge structures in $\mathrm{BaTiO}_{3}, \mathrm{Ba}(\mathrm{Ti}, \mathrm{Ru}) \mathrm{O}_{3}$ and $\mathrm{BaRuO}_{3}$.

Experiments were carried out on a FEI Tecnai-200FEG equipped with a monochromator and a high-resolution electron energy loss spectrometer as described previously [1]. While the overall structure of the $\mathrm{O}-\mathrm{K}$ edge is similar for $\mathrm{BaTiO}_{3}$ and the compounds with $\mathrm{Ru}$ substitutions, there are obvious differences in the details. The first peak at the edge threshold corresponds to the Ti $3 d-\mathrm{t}_{2 \mathrm{~g}}-$ $\mathrm{O} 2 p$ hybrid bands (or $4 d$ bands in $\mathrm{BaRuO}_{3}$ ) on the three systems. The peak is increasingly narrower in $\mathrm{Ba}(\mathrm{Ti}, \mathrm{Ru}) \mathrm{O}_{3}$ and $\mathrm{BaRuO}_{3}$ as compared to $\mathrm{BaTiO}_{3}$. At about $2.5 \mathrm{eV}$ above the threshold, however, the very weak peak corresponding to the Ti $3 d-\mathrm{e}_{\mathrm{g}}-\mathrm{O} 2 p$ in $\mathrm{BaTiO}_{3}$ and $\mathrm{Ba}(\mathrm{Ti}, \mathrm{Ru}) \mathrm{O}_{3}$ significantly differs from the $\mathrm{BaRuO}_{3}$. This suggests that in $\mathrm{Ba}(\mathrm{TiRu}) \mathrm{O}_{3}$, the $\mathrm{Ru} 4 d$ states strongly overlap with $\mathrm{T} i$ $3 d$ electrons and the role of $\mathrm{Ru}$ appears to be minor from the electronic point of view. This is in marked contrast with the near-edge structure in the hexagonal $\mathrm{BaRuO}_{3}$ where there are strong $\mathrm{Ru} 4 d$ $\mathrm{e}_{\mathrm{g}}$ hybrids with the $\mathrm{O} 2 p$ electrons. These latter states have been shown to arise from strong metalmetal bonding between adjacent $\mathrm{Ru}$ atoms in face-shared octahedra in recent electronic structure calculations [6]. The calculations also show that these states also strongly hybridize with the $\mathrm{O} 2 p$ bands as suggested in the experimental spectra. The first narrower peak in $\mathrm{BaRuO}_{3}$ also suggests that differences are present near the Fermi energy of the compounds. In fact, the electronic structure 
calculations show that the Fermi energy is located in the middle of the $\mathrm{Ru} 4 d \mathrm{t} 2 \mathrm{~g}$ band (whether the $4 \mathrm{H}$ or $9 \mathrm{H}$ hexagonal phase) thus indicating this compound is a metal (or semi-metal) as compared to $\mathrm{BaTiO}_{3}$. The trends and discussions based on existing electronic structure calculations show that electron energy loss spectra are therefore good probes of the electronic structure of perovskites and provide invaluable information to test detailed electronic structure calculations. Alternatively, the near-edge structures provide direct insight on the electronic properties of oxides. Similar effects are observed in the $\mathrm{Ba}(\mathrm{Ti}, \mathrm{Nb}) \mathrm{O}_{3}$ compound (figure 3 ) that has been shown to be a metallic oxide[7].

\section{References}

[1] S. Lazar, G.A. Botton, M.-Y.Wu, F.D. Tichelaar, H.W. Zandbergen, Ultram. 96 (2003), 535

[2] C. Mitterbauer et al., Ultram. 96 (2003), 469.

[3] S. Lazar, G.A. Botton, H.W. Zandbergen, Ultram 106 (2006), 1091

[4] J. G. Dickson, L. Katz, R. Ward, J. Amer. Chem. Soc. 83, (1961), 3026

[5] G. Radtke, C. Maunders, S. Lazar, F. M. F De Groot, J. Etheridge \& G. A. Botton, J. Solid State Chem. 178 (2005), 3426

[6] C. Felser and R.J. Cava, Phys. Rev. B, (2000), 61, 10005

[7] GAB is grateful to Prof. H. W. Zandbergen and to the NWO (Dutch Government) for access to the HREELS system. This work is supported by NSERC (Canada).

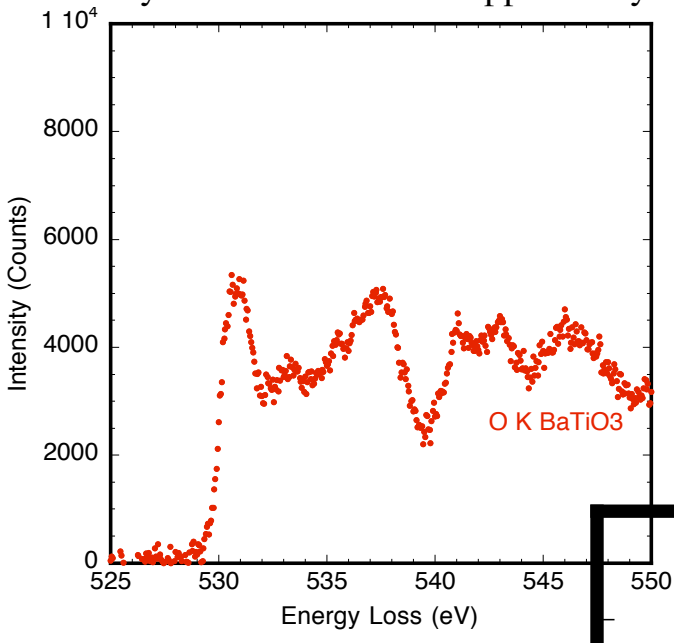

Figure 1) O-K edge in $\mathrm{BaTiO}_{3}$

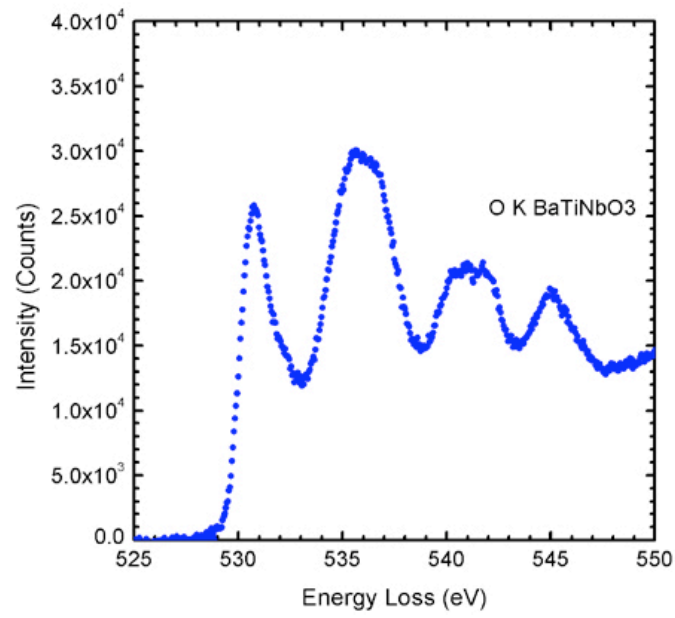

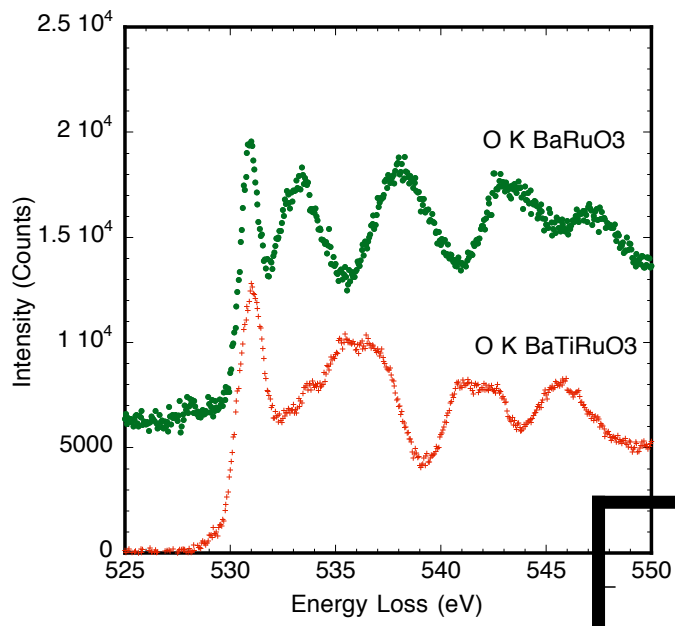

Figure 2) O-K edge in $\mathrm{BaRuO}_{3}$ and $\mathrm{Ba}(\mathrm{Ti}, \mathrm{Ru}) \mathrm{O}_{3}$

Figure 3) $\mathrm{O}-\mathrm{K}$ edge in $\mathrm{Ba}(\mathrm{Ti}, \mathrm{Nb}) \mathrm{O}_{3}$ 